Southern Illinois University Carbondale

OpenSIUC

Publications

Department of Civil and Environmental

Engineering

$9-2002$

\title{
Evaluation of InSpectra UV Analyzer for Measuring Conventional Water and Wastewater Parameters
}

Lizette R. Chevalier

Southern Illinois University Carbondale, cheval@engr.siu.edu

C. N. Irwin

Southern Illinois University Carbondale

J. N. Craddock

Southern Illinois University Carbondale

Follow this and additional works at: http://opensiuc.lib.siu.edu/cee_pubs

Published in Chevalier, L.R., Irwin, C.N. and Craddock, J.N., 2002. Evaluation of InSpectra UV

Analyzer for Measuring Conventional Water and Wastewater Parameters. Advances in

Environmental Research. 6(3):369-375. doi: 10.1016/S1093-0191(01)00098-3

\section{Recommended Citation}

Chevalier, Lizette R., Irwin, C. N. and Craddock, J. N. "Evaluation of InSpectra UV Analyzer for Measuring Conventional Water and Wastewater Parameters." (Sep 2002).

This Article is brought to you for free and open access by the Department of Civil and Environmental Engineering at OpenSIUC. It has been accepted for inclusion in Publications by an authorized administrator of OpenSIUC. For more information, please contact opensiuc@lib.siu.edu. 


\title{
Evaluation of InSpectra UV Analyzer for Measuring Conventional Water and Wastewater Parameters
}

Chevalier, L.R*, Irwin, C.N., and Craddock, J.N.

Department of Civil Engineering

Southern Illinois University Carbondale

MC 6603

Carbondale, IL 62901

Journal: Advances in Environmental Research, in press

\begin{abstract}
A relatively new analytical instrument for the measurement of $\mathrm{BOD}_{5}, \mathrm{COD}$, TSS, TOC, nitrates and surfactants has been developed commercially. It is based on the use of ultraviolet spectrophotometry and a deterministic approach to analyze the sample's spectrum by comparing it with a series of historical reference spectra. Using standard methods for the measurement of $\mathrm{BOD}_{5}, \mathrm{TSS}$ and TOC as true values, the use of this instrument was evaluated. The samples tested were obtained from both wastewater and water treatment facilities. Results indicate that the $\mathrm{BOD}_{5}$ measurement performed best. There was no correlation found for TSS or TOC.
\end{abstract}

\section{Introduction}

The InSpectra UV Analyzer is an ultraviolet (UV) spectrophotometer designed to measure water quality parameters including the five day biochemical oxygen demand $\left(\mathrm{BOD}_{5}\right)$, total organic carbon (TOC) and total suspended solids (TSS). The UV analyzer is based on the principal that the spectrum of any water sample is actually a composite of the spectra of its constituent parts including $\mathrm{BOD}_{5}, \mathrm{COD}, \mathrm{TSS}$, TOC, nitrates and 
surfactants. These different parts contribute to the information of the overall spectrum of the wastewater sample to different degrees depending upon their relative concentrations.

The UV analyzer uses a deterministic approach to analyze the sample's spectrum by comparing it with a series of historical reference spectra. The comparison uses an internal library with approximately 100,000 reference spectra and their corresponding chemical analyses (Azur Environmental, 2000). The UV analyzer determines the contribution coefficient for each reference spectra and, using the reference data stored in its internal UV-base software, estimates the spectrum of the whole sample. Once the system has selected the contribution coefficients that yield the spectrum of the sample test, the concentrations are computed and the results are displayed. The qualitative development is further discussed in Gallot and Thomas (1993a, b).

The UV analyzer potentially offers a wide variety of advantages over conventional water quality testing procedures, including real-time results collection, ease of operation, requiring no reagents, portability, operation variability, measurement of a wide range of parameters, data storage, and a PC interface. Of specific interest is the ease of operation and real-time results collection. This has many possible applications, including enabling treatment facilities to quickly react to changing water quality parameters.

Conventional UV analysis, which does not use internal historical reference spectra, has been used to measure organic carbon content, trihalomethane concentrations and color in treated and untreated water from municipal secondary sewage effluent and river water (e.g. Dobbs et al. 1972; Eaton. 1995). The use of the UV analyzer has been reported in 
published research focused on measuring the concentrations of industrial mixtures of aviation de-icers and anti-icers (Hartwell et al. 1995; Cancilla et al. 1998).

The objective of this study was to compare $\mathrm{TOC}, \mathrm{BOD}_{5}$ and $\mathrm{TSS}$ results from conventional analyses to the results obtained using the UV analyzer. The conventional analyses were performed as specified by Standard Methods for the Examination of Water and Wastewater (1998). The samples tested were obtained from the local water and wastewater treatment facilities.

\section{Methods and Materials}

\section{Site Description}

Wastewater samples were collected from the Northwest Wastewater Treatment Facility, Carbondale, Illinois during the summer of 2000. The treatment plant is a conventional activated sludge treatment facility, treating both industrial and residential sewage. Incoming industrial sewage, which is predominantly dairy waste, is pre-treated using primary sedimentation and a trickling filter system. Effluent from the industrial sewage treatment is mixed with the primary treated residential influent prior to the aeration tanks. The mixture is then treated using a conventional activated sludge process. The plant currently serves approximately 18,000 people with an average dry weather flow of 3400

$\mathrm{m}^{3} / \mathrm{d}$ and a wet weather flow of $4900 \mathrm{~m}^{3} / \mathrm{d}$. Plant capacity is currently $10,000 \mathrm{~m}^{3} / \mathrm{d}$. The industrial waste contributes approximately $1100 \mathrm{~m}^{3} / \mathrm{d}$ and $1900 \mathrm{~m}^{3} / \mathrm{d}$ for average dry and wet weather flows respectively. The untreated domestic influent averages approximately $95 \mathrm{mg} / \mathrm{L}$ of $\mathrm{BOD}_{5}$ and $85 \mathrm{mg} / \mathrm{L}$ of TSS whereas untreated industrial influent averages 
approximately $785 \mathrm{mg} / \mathrm{L}$ of $\mathrm{BOD}_{5}$ and $325 \mathrm{mg} / \mathrm{L}$ TSS. The plant yields a high quality effluent attaining removal rates of approximately $99 \%$ for $\mathrm{BOD}_{5}$ and $98 \%$ for TSS.

Water samples were obtained from the water treatment facility at Carbondale, Illinois during this same period. The facility supplies approximately 50,000 residents in several water supply districts. The plant capacity is presently $30,000 \mathrm{~m}^{3} / \mathrm{d}$, with an average flow of $17,500 \mathrm{~m}^{3} / \mathrm{d}$ and a peak of $22,700 \mathrm{~m}^{3} / \mathrm{d}$. The facility receives raw lake water from Cedar Lake. The facility employs a typical treatment scheme of settling tanks, decelerating flow filters and chlorination. In addition, the facility treats the water with a packed tower air stripper that removes about $90 \%$ of all trihalomethanes.

\section{Sampling}

Samples for $\mathrm{BOD}_{5}$ and TSS analysis were collected from three different stages of the wastewater treatment process: (1) raw wastewater samples (or influent) from the outlet to the grit-removal chamber, (2) treated domestic sewage (or effluent) at the inlet to the chlorination tanks, before chlorination, and (3) mixed liquor samples from the aeration tanks. All wastewater samples were collected in sterile one liter collapsible plastic bottles. Wastewater samples were analyzed immediately following collection, avoiding storage issues. In order to compare a wide range of concentrations, samples were diluted with tap water. The dilutions used were $25 \%, 50 \%, 75 \%$ and $100 \%$ by volume.

For TOC analysis, samples were collected from two different stage of the water treatment process: (1) raw lake water and (2) immediately following the decelarating filters (post filtered water). Samples were stored in $300 \mathrm{ml}$ glass sample bottles and stored at $4^{\circ} \mathrm{C}$ until use. 
$\mathrm{BOD}_{5}$ tests were performed according to Standard Methods for the Examination of Water And Wastewater (1998) Section 5210. No nitrification inhibitor was used in the stock BOD dilution water. To obtain $\mathrm{BOD}_{5}$, the following equation was used:

$$
B O D_{5}=\frac{\left(D O_{i}-D O_{f}\right)}{F}
$$

where $D O_{i}$ is the initial dissolved oxygen of the sample $(\mathrm{mg} / \mathrm{L}), D O_{f}$ is the dissolved oxygen after 5 days incubation $(\mathrm{mg} / \mathrm{L})$, and $F$ is the fractional dilution of the sample (i.e. the volume of the sample divided by volume of the BOD bottle). Two sample volumes were used for the influent, $6 \mathrm{~mL}(2 \%)$ and $15 \mathrm{~mL}(5 \%)$. For the effluent, the sample volumes were $120 \mathrm{~mL}(40 \%)$ and $240 \mathrm{~mL}(80 \%)$.

Dissolved oxygen was measured using a YSI model 5000 Dissolved Oxygen Meter equipped with a self-stirring BOD bottle probe (YSI model 5010). The YSI dissolved oxygen meter was calibrated prior to every test event. All $\mathrm{BOD}_{5}$ measurements were performed in triplicate.

\section{TSS Standard Method}

TSS tests were performed according to Standard Methods for the Examination of Water And Wastewater (1998) Section 2540 B. Crucibles and filters were initially heated to $550^{\circ} \mathrm{C}$ in a Fisher Isotemp Muffle Furnace Model $550-126$ and later dried at $105^{\circ} \mathrm{C}$ in a Fisher Isotemp Standard Oven 600 series model 637G. The ceramic crucibles and glass fiber filters (Whatman 934AH) were weighed using a covered Sartorius electronic scale. 
All weights were taken in grams to five decimal places. All TSS tests were run in triplicate.

\section{TOC Standard Method}

TOC measurements were performed according to Standard Methods for the Examination of Water And Wastewater (1998) Section 5310 B. Measurements were performed on a Formacs $^{\mathrm{HT}}$ Combustion TOC/TN Analyzer manufactured by Skalar. The Formacs TOC Analyzer uses the combustion method and is designed to be accurate to $1 \mathrm{mg} / \mathrm{L}$ of organic carbon.

\section{Inspectra UV Analyzer}

The instrument used in this study was an Inspectra UV Analyzer (model PASTEL-UV 70MP316). Azur Environmental advised the UV analyzer did not require calibration for the sample types investigated in this study. The UV analyzer does not require a warm-up time, although it does run a self test when switched on. Samples are placed in a $10 \mathrm{~mm}$ by $5 \mathrm{~mm}$ quartz cuvette and then placed in the instrument for measurement. As with standard UV analysis, care must be taken to prevent false readings due to trapped air bubbles or residue from fingers and cleaning cloth fibers. The cuvette was cleaned by rinsing with distilled water followed by acetone between samples.

The UV analyzer prompts the user to select the water type corresponding to the sample. Correctly matching the appropriate water type to the sample is essential to obtaining the best results possible (Table 1). Raw influent was analyzed as INFI, mixed liquor as INFI, treated effluent as $O U T B$, raw lake water and post filtered water as $N W A T$. Once the water type is entered the measurement and instrument response will take approximately 
forty-five seconds, after which the results are digitally displayed. The lower limit of detection for all TSS and $\mathrm{BOD}_{5}$ is $5 \mathrm{mg} / \mathrm{L}$. For $\mathrm{BOD}_{5}$, samples do not require the addition of dilution water or incubation. The lower detection limit for TOC is $0.5 \mathrm{mg} / \mathrm{L}$.

Table 1: Description of Instrument Displays

\begin{tabular}{|c|l||}
\hline Water Types & \multicolumn{1}{|c|}{ Definition } \\
\hline INFI & influent containing a maximum of 40\% industrial sewage \\
\hline OUTP & effluent of physical or chemical treatment process \\
\hline OUTB & effluent of biological treatment processes \\
\hline NWAT & water from rivers, lakes, wells, etc. \\
\hline
\end{tabular}

\section{Statistical Analysis}

The comparison of the two approaches are presented in graphs which show the results of the standard methods as the independent variable, and the results of the UV analyzer as the dependent variable. A trend following a line at $45^{\circ}$ would visually indicate a strong correlation. A correlation coefficient $\mathrm{R}^{2}$ was determined between the two techniques based on:

$$
\begin{aligned}
& R^{2}=\frac{S_{t}-S_{r}}{S_{t}} \\
& S_{t}=\sum_{i=1}^{n}\left(y_{i}-\bar{y}\right)^{2} \\
& S_{r}=\sum_{i=1}^{n} e^{2}=\sum_{i=1}^{n}\left(y_{m}-y_{i}\right)^{2}
\end{aligned}
$$


where $y_{i}$ is the dependent data measured by the UV analyzer, $\bar{y}$ is the average of dependent data, $n$ is the number of data points, and $y_{m}$ is the independent data measured by standard methods.

\section{Results and Discussion}

$\mathrm{BOD}_{5}$

Samples were obtained from both the influent and effluent flow of a wastewater treatment facility. As reported earlier, the lower detection limit of the UV analyzer is 5 $\mathrm{mg} / \mathrm{L}$. Measurements of the effluent results in numerous samples with a $\mathrm{BOD}_{5}$ less than $5 \mathrm{mg} / \mathrm{L}$, hence much of the data obtained from the effluent was not compared to results from the UV analyzer.

The range of $\mathrm{BOD}_{5}$ values from the standard method was $5.8 \mathrm{mg} / \mathrm{L}$ to $122.5 \mathrm{mg} / \mathrm{L}$. The corresponding range of values measured using UV analysis was $5 \mathrm{mg} / \mathrm{L}$ to $92 \mathrm{mg} / \mathrm{L}$. The results are shown in Figure 1. The correlation was 0.62. Further consideration of the differences were elucidated by calculating the relative percent error based on:

$$
\text { error }=\left|\frac{\text { real }- \text { estimate }}{\text { real }}\right| \times 100
$$

where the real value is the value obtained from standard methods and the estimate is the value measured by the UV analyzer. The results of this evaluation are presented in Figure 2. The error ranges from $1.5 \%$ to $103 \%$, with an average error of $30 \%$. Figure 2 indicates that the error is less at $\mathrm{BOD}_{5}$ values greater than approximately $50 \mathrm{mg} / \mathrm{L}$.

Since each data point in Figures 1 and 2 was measured in triplicate, additional analysis of the data was conducted to determine precision (repeatability) and confidence. For each 
triplicate set of data, a confidence interval of $95 \%$ was assumed and the error determined using the following:

$$
\text { error }=1.96 \frac{\sigma_{y}}{\sqrt{n}}
$$

where the $\sigma_{y}$ is the standard deviation of the respective data set and $n$ is the population size (in this case 3). The upper and lower values of the error were then determined using:

$$
\bar{y} \pm 1.96 \frac{\sigma_{y}}{\sqrt{n}}
$$

The results of the analysis of the error of each triplicate data set are presented in Figures 3 and 4. The data was sorted in ascending order. The sample number is reported on the $\mathrm{x}$-axis, therefore the highest sample number represents the highest reading. Results for standard method $\mathrm{BOD}_{5}$ show the greatest error at approximately $80 \mathrm{mg} / \mathrm{L}$. In general, this error ranges from $\pm 0.42 \mathrm{mg} / \mathrm{L}$ to $\pm 44.47 \mathrm{mg} / \mathrm{L}$, with an average error of $\pm 10.65 \mathrm{mg} / \mathrm{L}$. As seen in Figure 4, the UV analyzer results are more precise, ranging between $0.00 \mathrm{mg} / \mathrm{L}$ to $\pm 6.88 \mathrm{mg} / \mathrm{L}$, with an average error of $\pm 1.95 \mathrm{mg} / \mathrm{L}$.

\section{TSS}

Samples were obtained from both the influent and effluent flow of a wastewater treatment facility. TSS values measured using standard methods ranged between 10.6 $\mathrm{mg} / \mathrm{L}$ to $170.8 \mathrm{mg} / \mathrm{L}$, which are above the lower detection limit of the UV analyzer. The corresponding range of TSS values using UV analysis was $6 \mathrm{mg} / \mathrm{L}$ to $202 \mathrm{mg} / \mathrm{L}$. The results are shown in Figure 5. The correlation is negative due to the larger residual error, $S_{r}$ compared to $S_{t}$. The relative percent error ranged from 0 to $250 \%$, with an average 
error of $72 \%$. Unlike the $\mathrm{BOD}_{5}$ analysis (Fig. 2), there is no clear trend to suggest that the error is greater or smaller over a range of TSS values. As with $\mathrm{BOD}_{5}$, the confidence interval from triplicate measurements was evaluated for both methods (Fig. 6-7). For the standard method of TSS analysis, the error increases at TSS values between $56 \mathrm{mg} / \mathrm{L}$ and $109 \mathrm{mg} / \mathrm{L}$, but then decreases to some extent at the higher values. The error ranges from $\pm 0.54 \mathrm{mg} / \mathrm{L}$ to $\pm 56.36 \mathrm{mg} / \mathrm{L}$, with an average error of $\pm 11.42 \mathrm{mg} / \mathrm{L}$. Somewhat similar results were obtained from the UV analyzer (Fig. 11). Here, the error ranged from \pm 0.65 $\mathrm{mg} / \mathrm{L}$ to $\pm 55.95 \mathrm{mg} / \mathrm{L}$, with an average error of $\pm 9.01 \mathrm{mg} / \mathrm{L}$. This indicates more that the UV analyzer was more precise (reproducible), though not as strongly as it was with respect to $\mathrm{BOD}_{5}$ analysis.

TOC

In this analysis, both raw and post filtered (treated) water were evaluated. The TOC analysis was performed in collaboration with the Carbondale Water Treatment Plant. The treatment facility provided TOC measurements from their laboratory with duplicate sample for in-house measurements using the UV analyzer. Therefore, analysis was not conducted in triplicate. The results of the comparison of the two analytical techniques are presented in Figure 8.

TOC raw water measurements using standard methods ranged from $5.3 \mathrm{mg} / \mathrm{L}$ to 7.1 $\mathrm{mg} / \mathrm{L}$. The corresponding range of values from the UV analyzer ranged between 2.3 $\mathrm{mg} / \mathrm{L}$ to $6.2 \mathrm{mg} / \mathrm{L}$. As with the TSS, the correlation was negative due to the large value of the residual error, $S_{r}$. The percent error between the methods ranged between $17 \%$ to 
$68 \%$, with an average error of $43 \%$. Unlike $\mathrm{BOD}_{5}$ (Fig. 2), there was no apparent trend in the percentage error between the methods.

TOC measurement using standard methods on the post filtered water ranged from 2.7

$\mathrm{mg} / \mathrm{L}$ to $3 \mathrm{mg} / \mathrm{L}$. The corresponding UV analyzer TOC measurements ranged between 1.2 $\mathrm{mg} / \mathrm{L}$ to $3.5 \mathrm{mg} / \mathrm{L}$. The correlation was negative due to the high value of $S_{r}$. The percentage error between the two methods ranged from $13 \%$ to $56 \%$ with an average of 42\%. Unlike $\mathrm{BOD}_{5}$ (Fig. 2), there was no apparent trend in the percentage error between the methods.

\section{Comparison to Product Literature}

Figures 9-10 are graphs from the product literature for the UV analyzer. Unlike the analysis in this paper, the UV analyzer is the independent variable. In Figure 9, the BOD is compared over an approximate range of $10 \mathrm{mg} / \mathrm{L}$ to $60 \mathrm{mg} / \mathrm{L}$. In comparison, Figure 1 reports values in the range $5.8 \mathrm{mg} / \mathrm{L}$ to $122.5 \mathrm{mg} / \mathrm{L}$. An additional comparison between the methods was conducted using the $\mathrm{BOD}_{5}$ data from $\mathrm{UV}$ analyzer as the independent variable for data less than $60 \mathrm{mg} / \mathrm{L}$ (Fig. 11). In this analysis, $\mathrm{R}^{2}$ increased from 0.61 to 0.76. In the previous analysis, the relative error decreased at $\mathrm{BOD}_{5}>50 \mathrm{mg} / \mathrm{L}$ (Fig. 2), which suggests that the results may have improved at higher values for the testing done by the manufacturer.

In Figure 10, TSS is compared over an approximate range of 20 to $250 \mathrm{mg} / \mathrm{L}$, which is higher than the range used in this study $(5$ to $150 \mathrm{mg} / \mathrm{L})$. Over half of the data points are in a range less than $60 \mathrm{mg} / \mathrm{L}$, which compares to the trend of the effluent wastewater data in Figure 5. For comparison, the effluent data only is reported in Figure 12. The 
scattered data indicates a weak correlation, consistent with the results presented in Figure

5.

\section{Summary}

Using samples from wastewater and water treatment facilities, the use of the UV analyzer to measure conventional water quality parameters was evaluated. Standard methods for measuring these parameters were used as a benchmark. The water quality parameters used were $\mathrm{BOD}_{5}$, TSS and TOC. The evaluation considered the accuracy of the UV analyzer as well as the precision of both methods.

Of the three water quality parameters, the UV analyzer predicted $\mathrm{BOD}_{5}$ with the highest degree of accuracy. Based on the error analysis of triplicate measurements, the UV analyzer was more precise in measuring $\mathrm{BOD}_{5}$. Although the $\mathrm{UV}$ analyzer results did not agree with the standard methods for TSS, again the method was more precise (reproducible). Finally, the TOC results from the UV analyzer were not in agreement with results from standard methods.

This study did not use an independent lab to provide additional data comparison, which would be necessary to support any further conclusions. Additional studies are planned to compare TOC for prepared samples using humic and fulvic acid, hence removing the potential interference to UV readings from colloidal or suspended solids present in the lake water.

\section{Reference}


Azur Environmental 2000. InSpectra ${ }^{\mathrm{TM}}$ One Minute BOD, COD, TOC, TSS, nitrates and surfactants. http://www.azurenv.com/ (9/07/2000) Inspectra.

Cancilla, D.A., Martinez, J. and Van Aggelen G.C. 1998. Detection of aircraft deicing/antiicing fluid additives in a perched water monitoring well at an international airport. Environmental Science and Technology 32(23), 3834-3835.

Dobbs, R.A., Wise, R.H., and Dean, R.B. 1972. The use of ultra-violet absorbance for monitoring the total organic carbon content of water and wastewater. Water Research 6(10), 1173-1180.

Eaton, A. 1995. Measuring UV absorbing organics: A standard method. Journal of American Water and Wastewater Association 87(2),86-90.

Edward, J. K., Becker, W.C., and Wattier K.L. 1985. Surrogate parameters for monitoring organic matter and THM precursors. Journal of American Water and Wastewater Association 77(4), 122-132.

Gallot, S. and Thomas, O., 1993a. Fast and easy interpretation of a set of absorption spectra: theory and qualitative applications for UV examination of waters and wastewaters. Fresenius Journal of Analytical Chemistry 346(10-11), 976-983.

Gallot, S. and Thomas, O., 1993b. State of the art for the examination of UV spectra of waters and wastewaters. International Journal of Environmental Analytical Chemistry 52(1-4), 49-158.

Hartwell, S.I., Jordahl, D.M., Evans, J.E. and May, E.B. 1995. Toxicity of aircraft de-icer and anti-icer solutions to aquatic organisms. Environmental Toxicity and Chemistry 14(8), 1375-1386.

Standard Methods for the Examination of Water and Wastewater, 20 ${ }^{\text {th }}$ Ed. 1998. APHA, AWWA and WEF, Washington, D.C. 


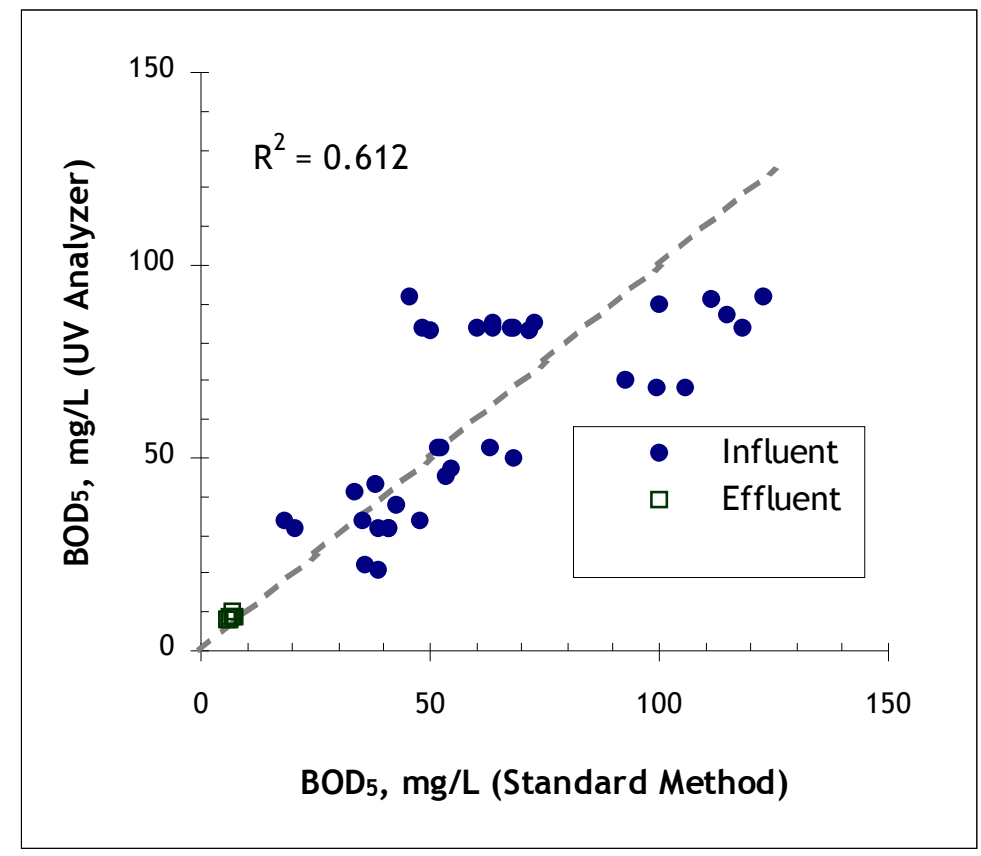

Figure 1: Comparison of $\mathrm{BOD}_{5}$ analysis using standard methods and the UV analyzer.

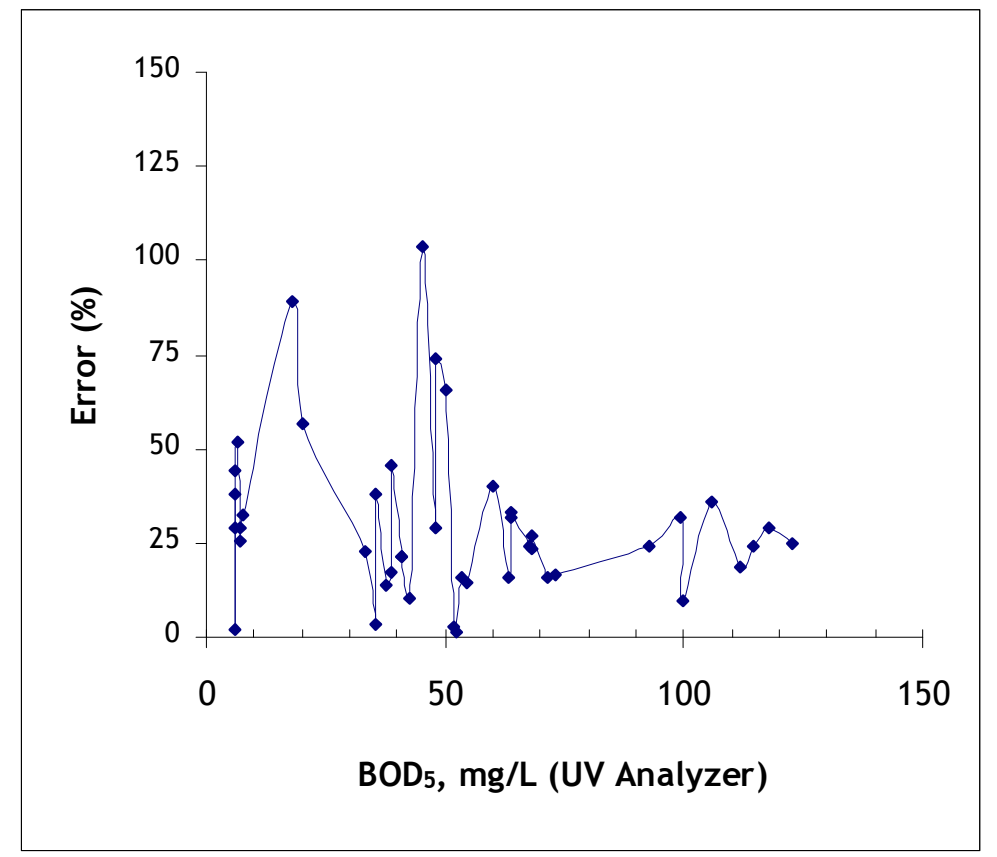

Figure 2: Evaluation of error between methods for $\mathrm{BOD}_{5}$. 


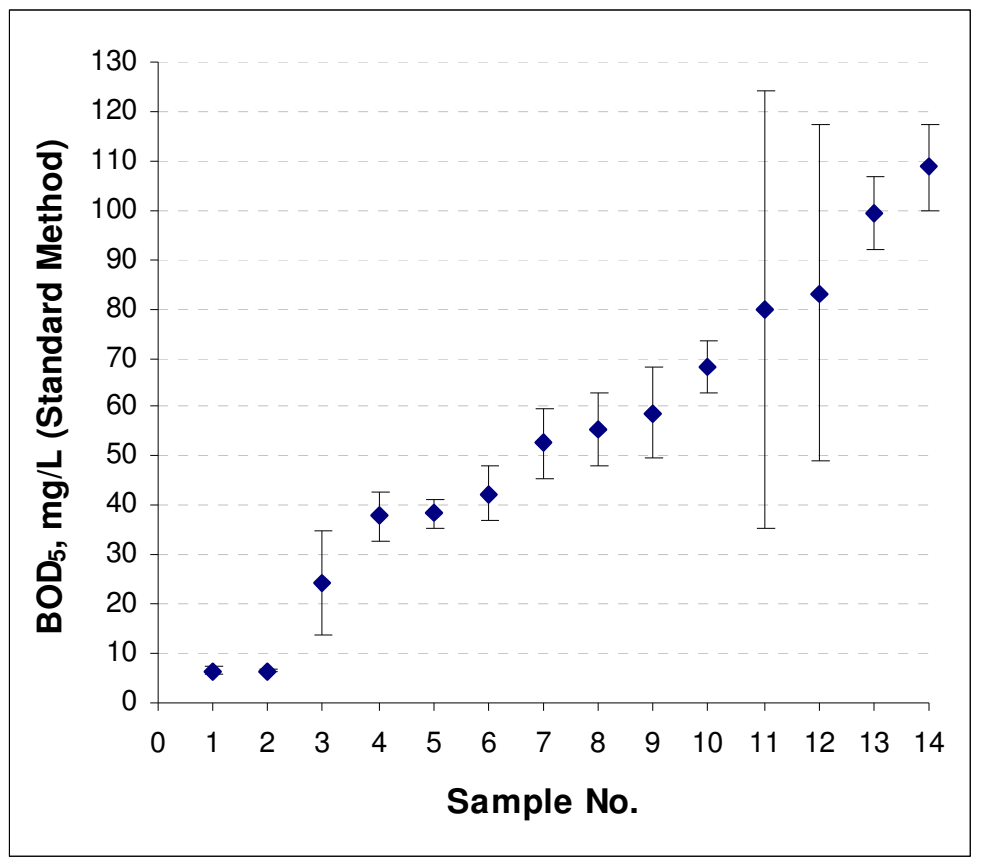

Figure 3: Analysis of the precision of standard method measurement of $\mathrm{BOD}_{5}$

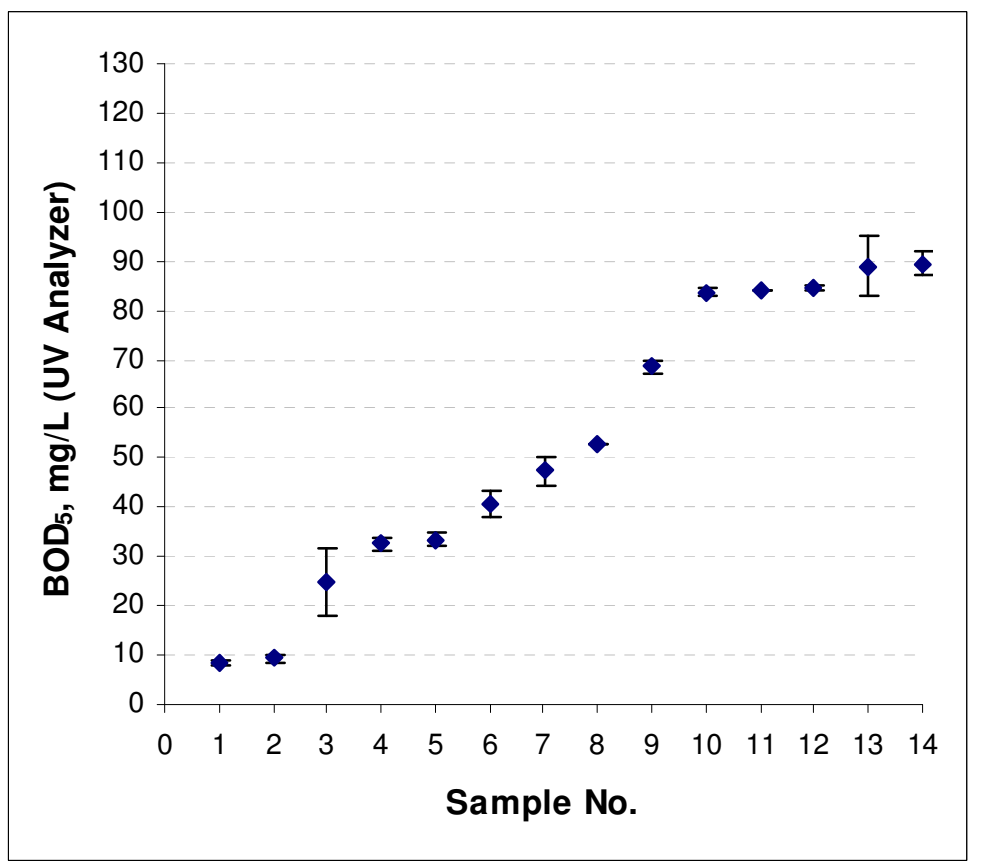

Figure 4: Analysis of the precision of UV analyzer measurement of $\mathrm{BOD}_{5}$ 


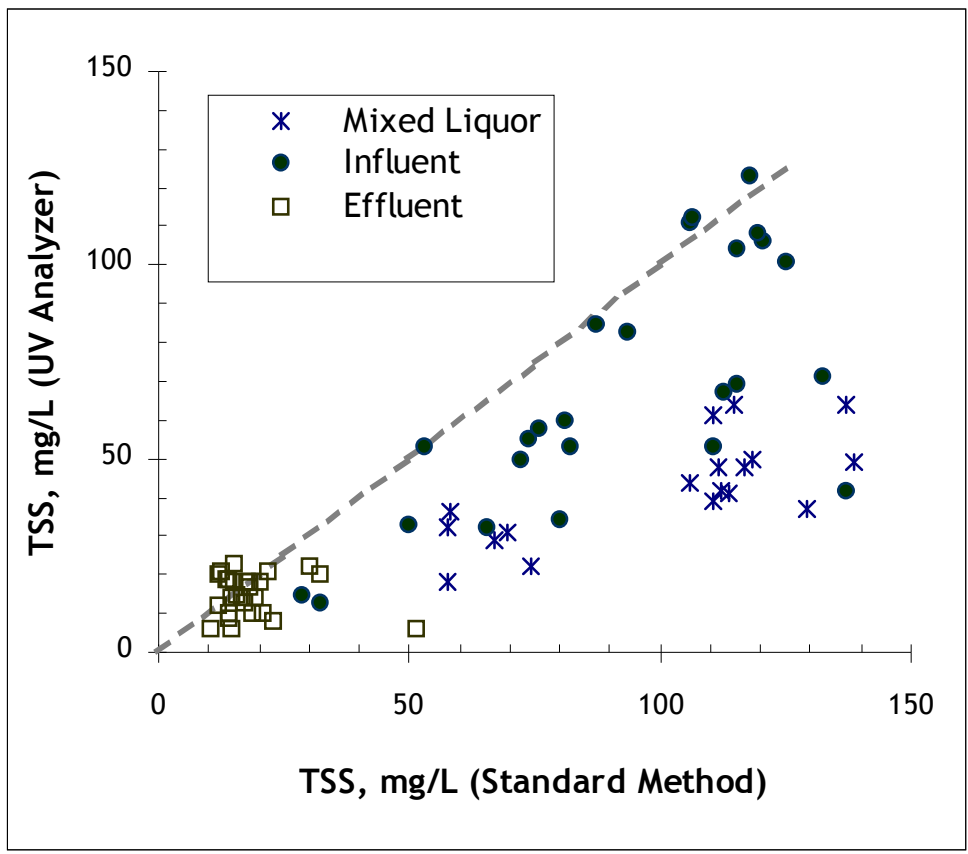

Figure 5: Comparison of TSS analysis using standard methods and the UV analyzer. 


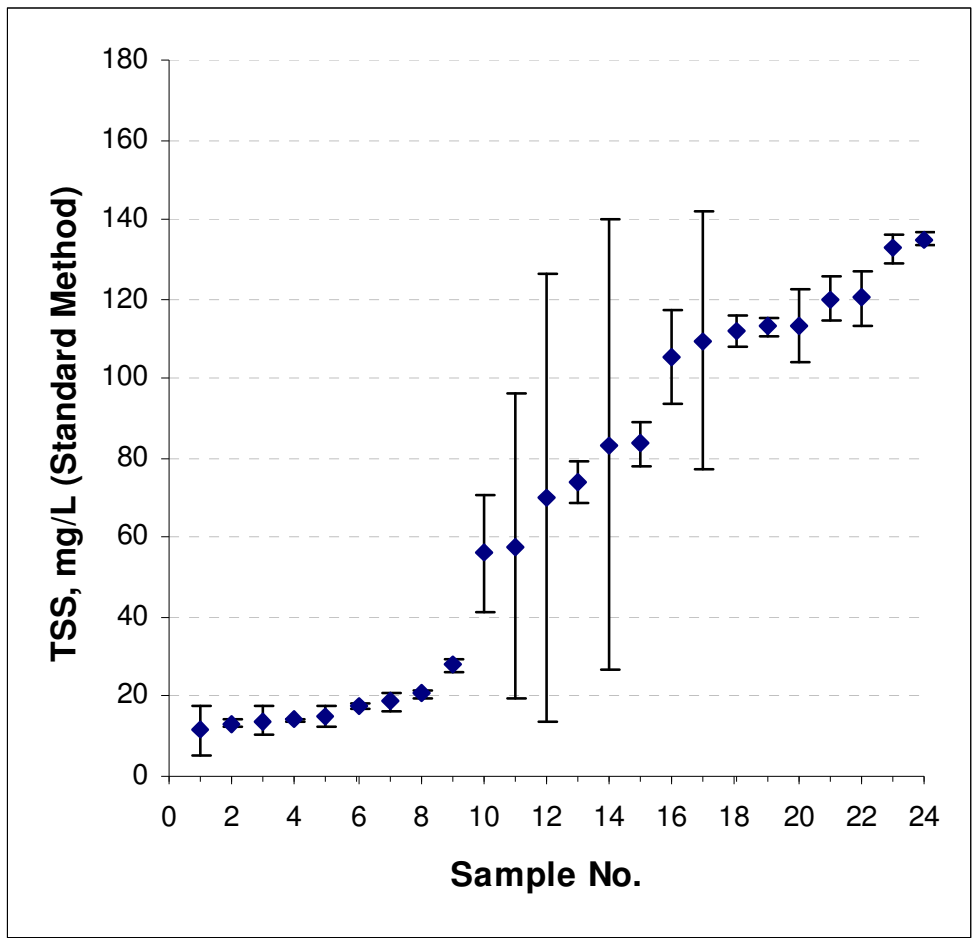

Figure 6: Analysis of the precision of standard method measurement of TSS.

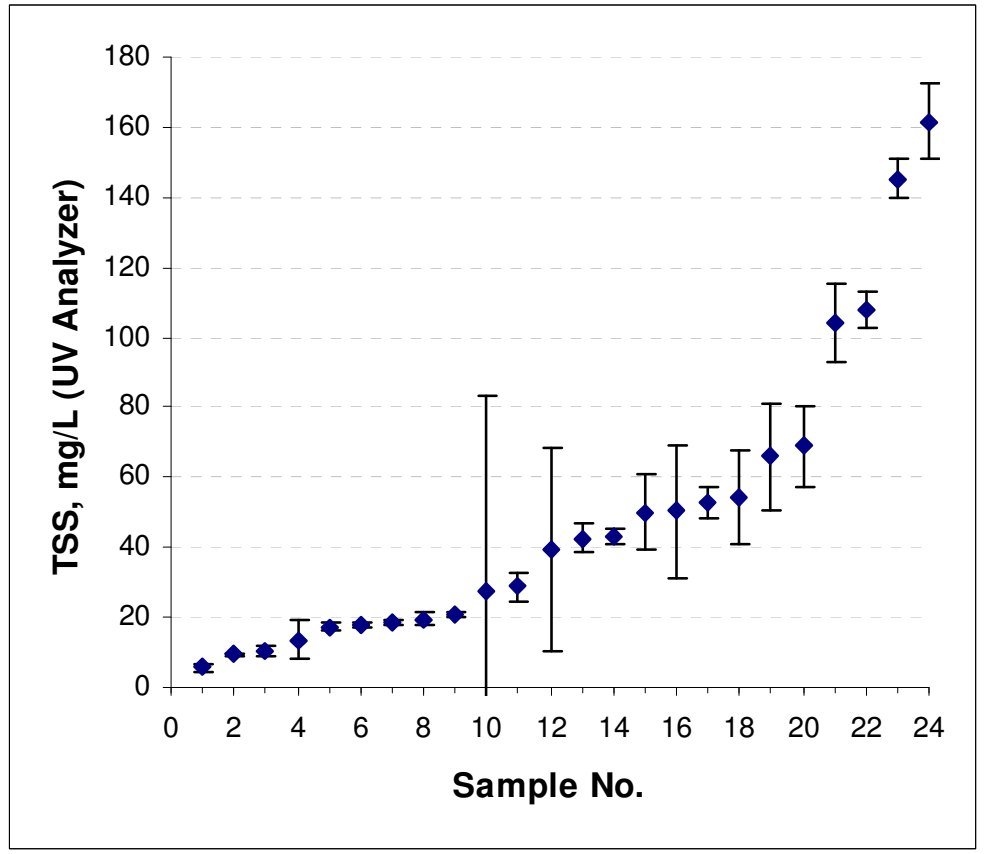

Figure 7: Analysis of the precision of UV analyzer measurement of TSS. 


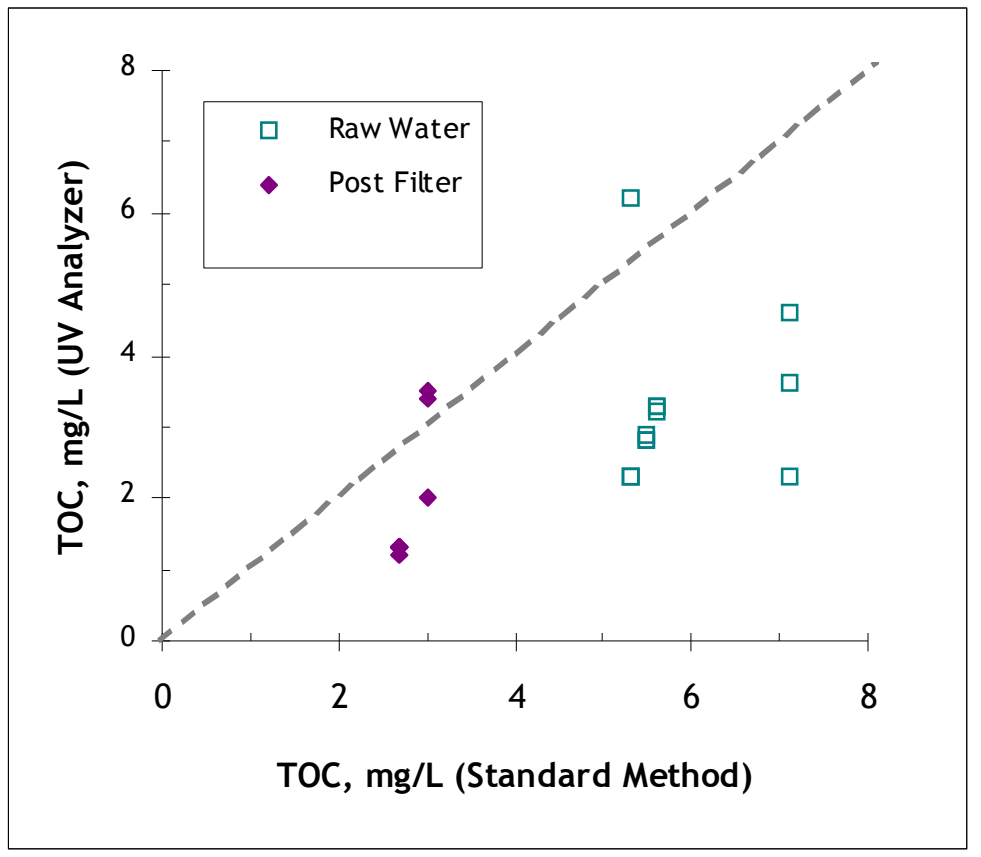

Figure 8: Comparison of TOC analysis using standard methods and the UV analyzer.

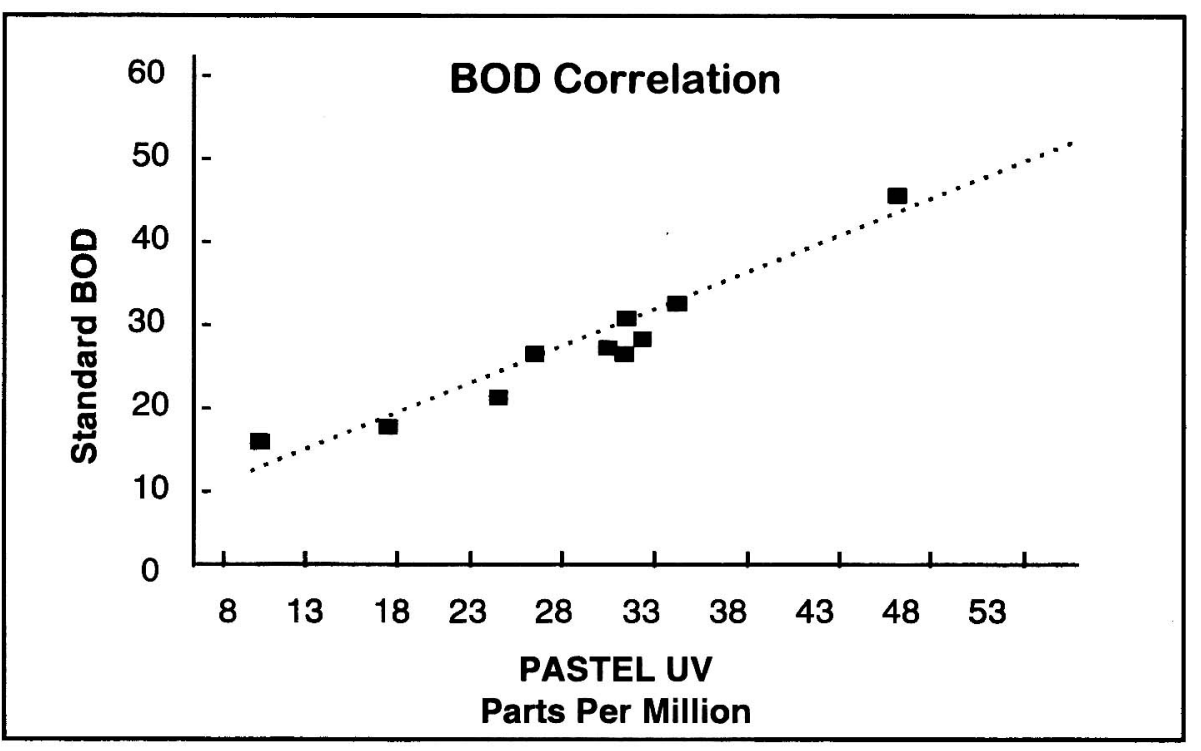

Figure 9: Comparison of UV analyzer and standard method measurement of $\mathrm{BOD}_{5}$ from the product literature. 


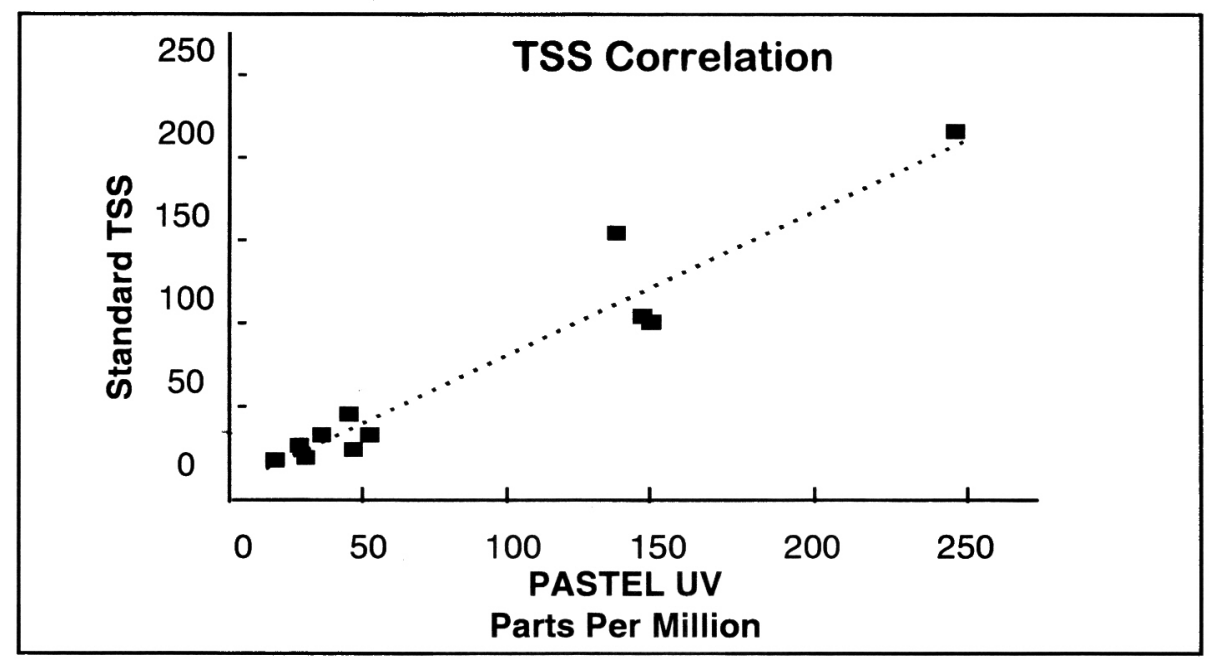

Figure 10: Comparison of UV analyzer and standard method measurement of TSS from the product literature.

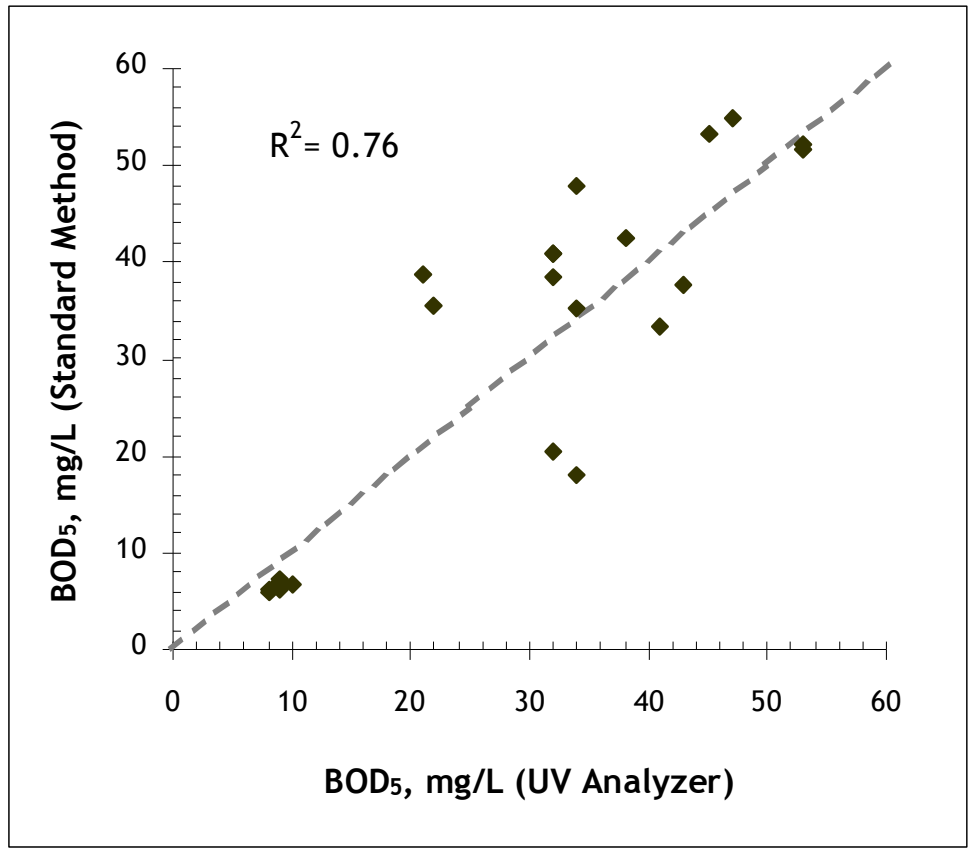

Figure 11: Comparison of $\mathrm{BOD}_{5}$ analysis using standard methods and the UV analyzer for BOD5 < $60 \mathrm{mg} / \mathrm{L}$. 


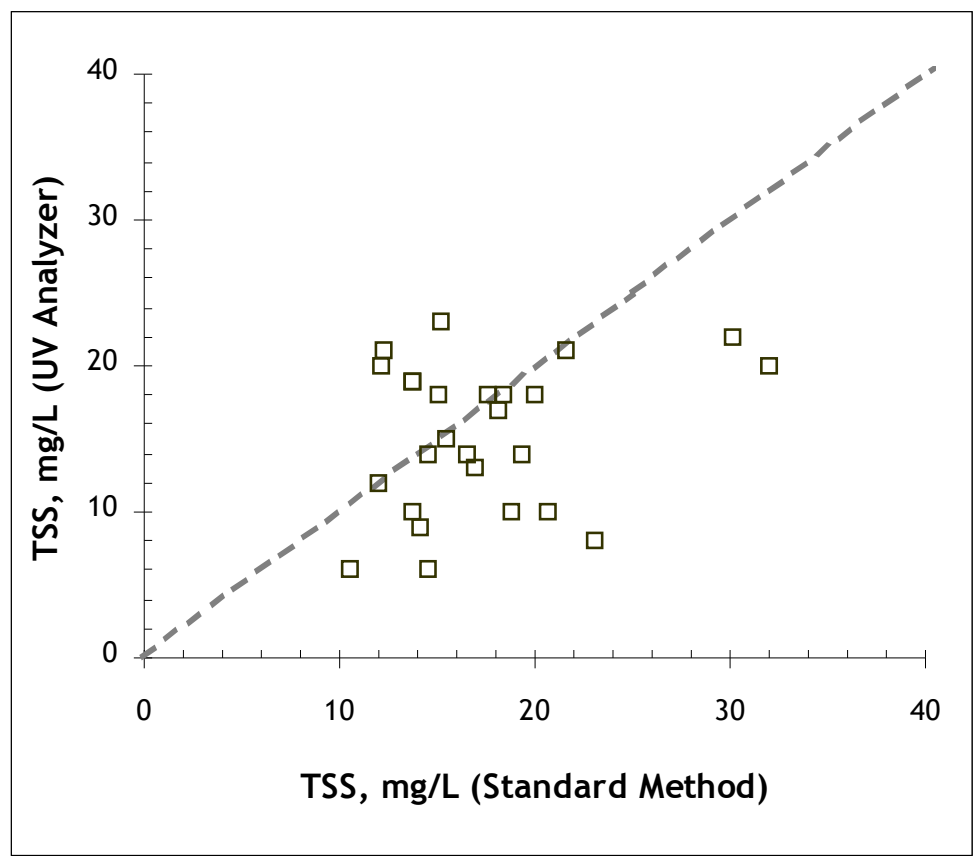

Figure 12: Comparison of TSS analysis using standard methods and the UV analyzer using only the effluent wastewater samples. 